\title{
Estimation of in situ strength from back-analysis of pit slope failure
}

\author{
IR Brown TAGA Engineering Software Ltd, New Zealand \\ PJ Wood TAGA Engineering Software Ltd, New Zealand \\ MK Elmouttie CSIRO Energy, Australia
}

\begin{abstract}
Using a software package that can be used for either three or two-dimensional (2D) slope stability analyses of the same model we analyse the stability of columns (3D) or slices (2D) overlying a shear failure surface. The failure surface can be any shape, such as that formed by interconnecting fault surfaces in an open pit slope failure that we analyse. We show that there is a significant difference in the factors of safety calculated using $3 D$ analyses, compared with $2 D$ sections through the same model. This means that different shear strength parameters will apply when the values are varied to obtain a Factor of Safety of 1.0. Systematic back-calculations of open pit slope failures using appropriate 3D analysis methods can give a better understanding of appropriate shear strengths to use in forward 3D analyses. This should lead to more efficient pit slope designs.
\end{abstract}

\section{Introduction}

Back-analysis is an approach commonly used in geotechnical engineering to help estimate the appropriate properties of an in situ rock or soil mass. When applied to slope engineering, it may be used to analyse an apparently stable slope, in which case we are able to estimate the minimum operating shear strengths. When back-analysis is used to forensically investigate a failed slope, then we should be able to use the results to estimate the average shear strength along the failure surface at the time of failure.

This paper shows how the strengths estimated from back-analysis of a pit slope failure are dependent on the slope model used, all other factors being the same.

Duncan et al. (2014) includes a chapter titled "Analyses to back-calculate strengths" that provides a comprehensive discussion on the topic. They make the case that "when a slope fails by sliding, it can provide a useful source of information on the conditions in the slope at the time of the failure as well as an opportunity to validate stability analysis methods".

As part of the development of a three-dimensional (3D) slope stability analysis program TSLOPE (TAGAsoft 2016), we have used a pit slope failure described by Chapple (1998) to help with validation of our slope stability calculations. Early validation of our 3D code involved testing simple analytical solutions, however they lack the complexity of real world problems provided by well-documented failures of slopes in different geological settings.

A further benefit of our validation using back-analysis is the opportunity to compare the results (3D and 2D) with other slope stability models. An alternative model that is discussed in this paper was provided by Siromodel (Elmouttie et al. 2016).

\section{TSLOPE approach to slope stability analysis}

Limit equilibrium procedures are used in many slope stability analysis programs. Calculations involve estimating a Factor of Safety (FS) using one of the commonly used procedures of analysis. Most procedures use the same definition for the FS; that is a factor by which the shear strengths need to be divided in order 
to obtain equilibrium. The shear strength is most often calculated using the Mohr-Coulomb shear strength criterion.

To calculate a FS for a slope, a failure surface is required. This is either determined by local rock structure, or estimated based on an algorithm that searches for a shape with minimum resistance to sliding. Using the failure surface geometry, the appropriate equations of static equilibrium are used to calculate the stresses and FS for that failure surface.

A TSLOPE user builds a slope model with the appropriate 3D geological surfaces. These include the ground surface, failure surface, and phreatic surface. The model is discretised into square columns that overly the failure surface, and the program then applies the appropriate rock parameters (density, cohesion, friction angle) to the failure surface, and calculates the sliding direction and the FS for that slope case.

TSLOPE uses two procedures for carrying out slope stability analyses. The first is a procedure that has its origins in what has been known in 2D as the Ordinary Method of Slices. This method does not transfer forces between vertical columns, and we define the FS simply as the ratio of the sum of resisting forces over the sum of driving forces acting at the base of each column. This is different to the definition referred to above. A useful feature of this method is that we calculate a FS at the base of each column. The distribution of these local factors of safety can show which parts of the slope are driving slope failure, and an indication of the potential for progressive failure.

There are many procedures that have been developed for limit equilibrium stability analysis, however we have found that Spencer's Method (Spencer 1967) provides the simplest complete equilibrium procedure. We have extended the $2 \mathrm{D}$ method to $3 \mathrm{D}$, and have a search routine to determine the appropriate side force angle to provide force and moment equilibrium. We also use minimisation to determine the best estimate for global equilibrium (full force and moment equilibrium), including sliding direction. For symmetric problems, achieving 'exact' global equilibrium is often possible. For asymmetric problems, TSLOPE typically gets within a few percent of 'exact' global equilibrium. The method is robust; it also calculates out of balance forces and moments, thus providing an estimate for the 'error' of the result. The minimisation routine adjusts the parameters FS, sliding direction, and side force angles to achieve as close as possible full force and moment equilibrium, which means the sum of the forces and sum of moments are zero with respect to $x, y$, and $z$ directions.

\section{Round Hill open pit slope failure}

\subsection{Slope setting}

The Round Hill open pit was the first modern open pit worked at Macraes Flat in the South Island of New Zealand (Lee et al. 1989). Mineralisation at Round Hill is hosted by quartzo-feldspathic psammo-pelitic schists, with the ore body comprising a shallow-dipping shear system.

Significant structures (shears, faults) are present, and depending on relative orientations to the open pit, they can have an adverse effect on pit slope stability.

In 1996 a pit slope failure affected the northern slope of Round Hill open pit (Figure 1). The failure, designated RH28, was well documented by mine staff, and was studied as part of a university thesis (Chapple 1998).

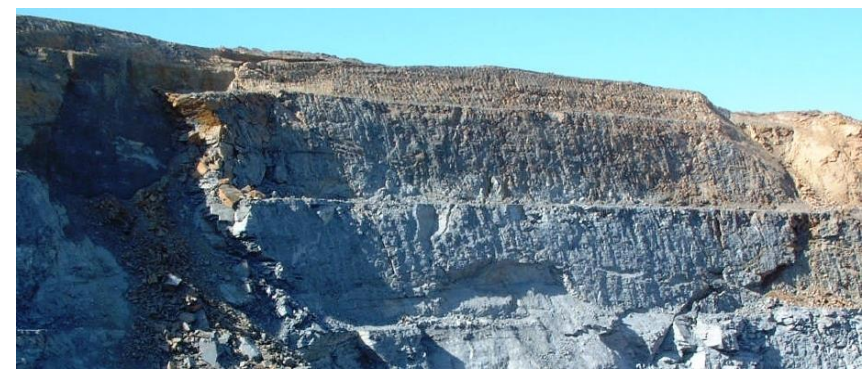

Figure 1 Photograph showing the RH28 pit slope failure on the northern wall of Round Hill pit 
The slope failure was controlled by four faults, their intersection defining a failure surface that allowed sliding towards the open pit. The faults were not planar; they comprised in part low strength gouge material that was difficult to sample for laboratory shear testing. Where such tests were carried out, a residual shear strength of less than $10^{\circ}$ (zero cohesion) was measured.

\subsection{Slope model}

A detailed geological plan of the $\mathrm{RH} 28$ failure area was used to model each of the four fault surfaces using Leapfrog3D ${ }^{\circledR}$ (ARANZ Geo 2016), a geological modelling package, and each surface was imported to TSLOPE. The resulting surfaces honoured the outcrop pattern, and were further constrained by the structural orientation observations.

A composite failure surface was defined by three of the faults (Figure 2). One of the faults (darker shaded, to right of Figure 2) dips into the slope and to accurately model the slope failure it was composited with the pit slope surface so that the overhanging rock was not acting on the failure surface at the point of failure.

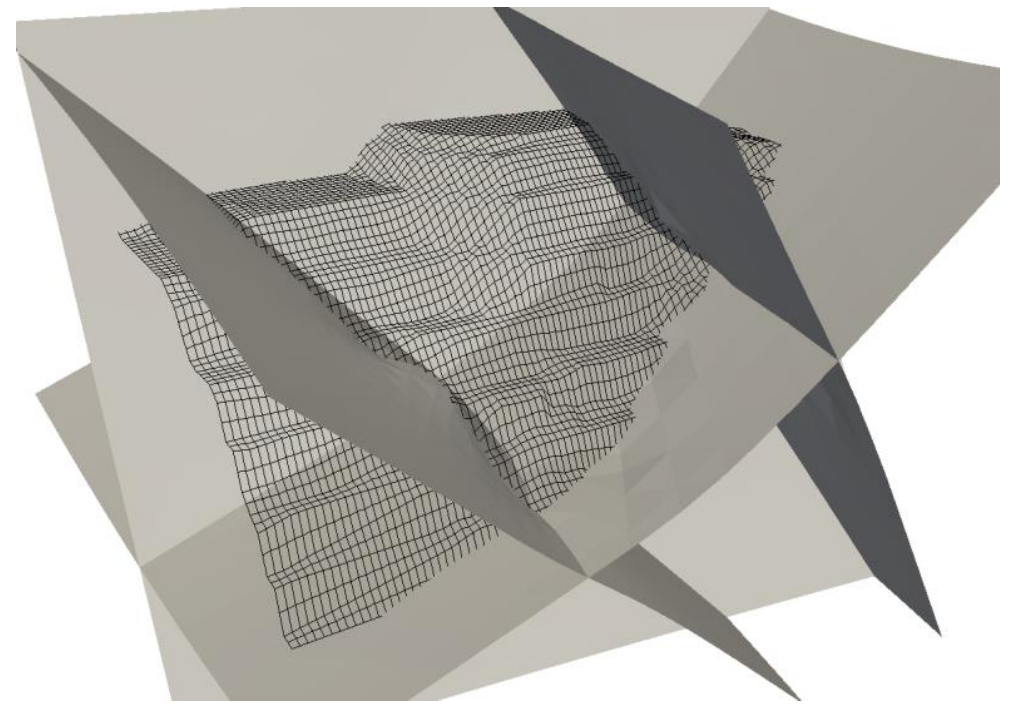

Figure 2 Slope model showing pit slope (wire frame) and intersecting fault surfaces

A phreatic surface was also modelled using observations of groundwater prior to slope failure.

The discretised slope is shown in Figure 3; in this case each rock column has sides of $4 \mathrm{~m}$.

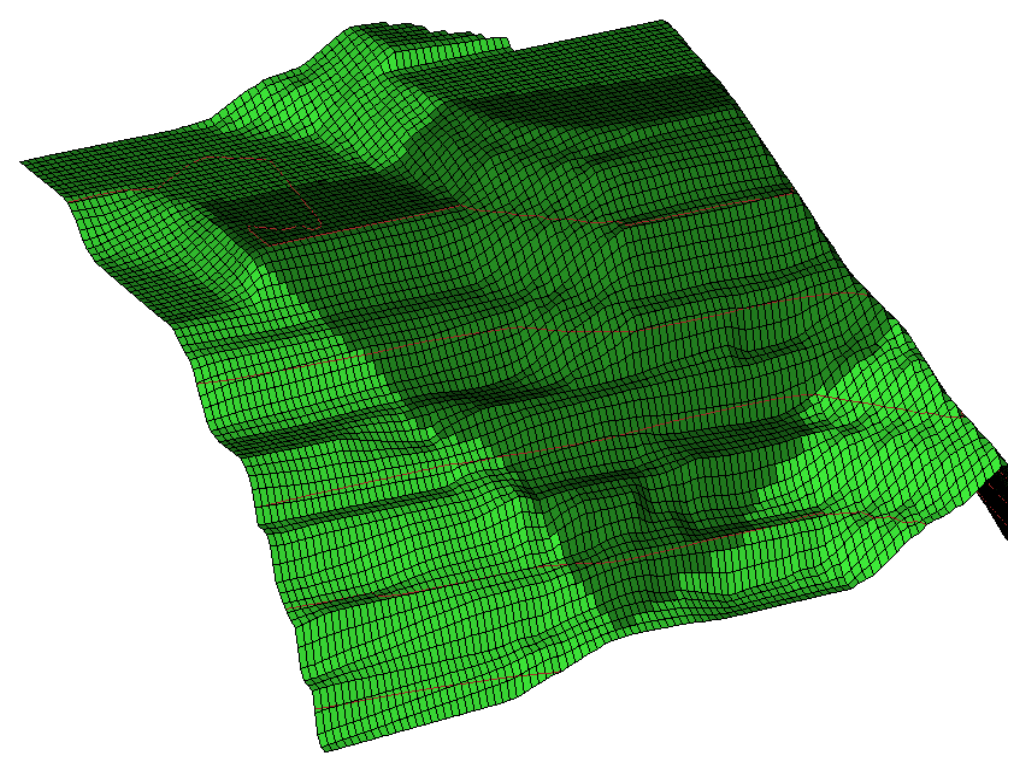

Figure 3 Slope model showing rock columns (dark shading) overlying composite failure surface 


\section{$4 \quad$ Results}

\subsection{D slope stability calculations}

Using the back-analysis type of analysis, we obtained a cross plot of friction angle versus cohesion at intervals of FS (Figure 4). In this case, Spencer's Method of limit equilibrium analysis was used to provide the result. The computed friction angle for a FS of unity was $25^{\circ}$ (zero cohesion) significantly higher than measured by laboratory testing.

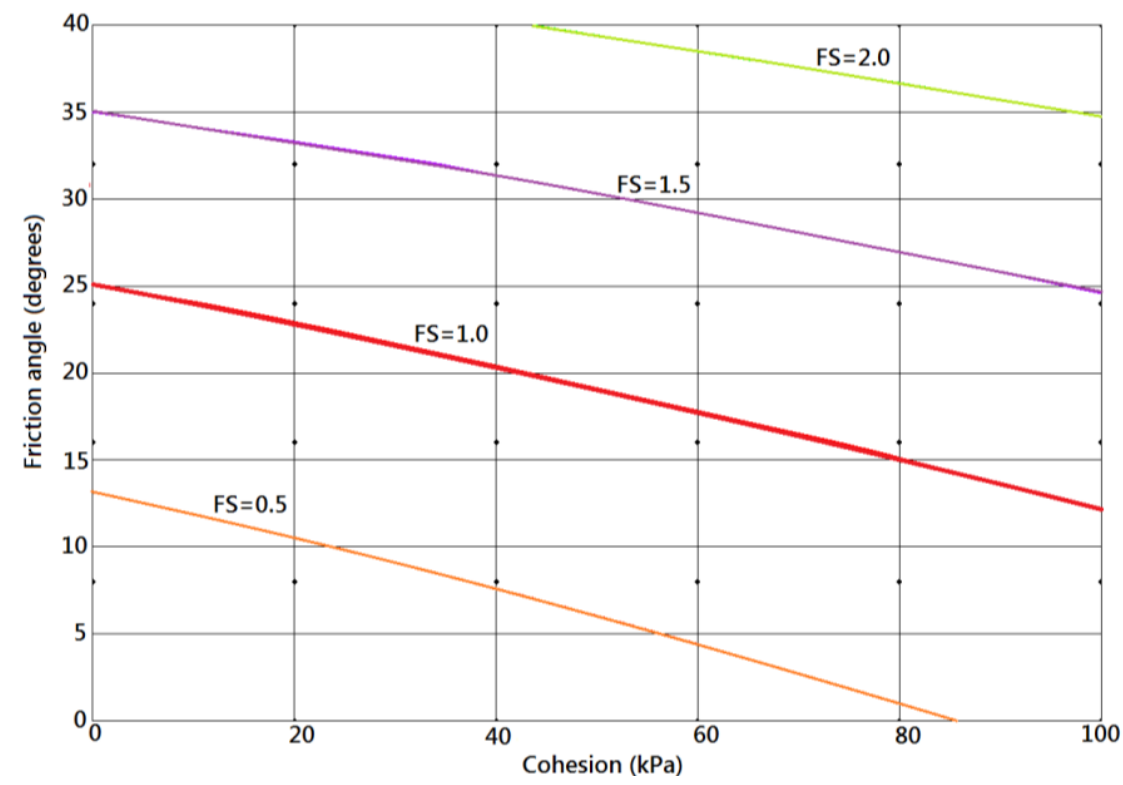

Figure 4 3D slope - friction angle versus cohesion for intervals of FS

\subsection{D slope stability calculations}

Using the 3D model described above, we are able to construct a cross section across the model in the direction of sliding (Figure 5), and use the same method of analysis (Spencer's) to calculate a comparable cross plot of strength parameters (Figure 6).

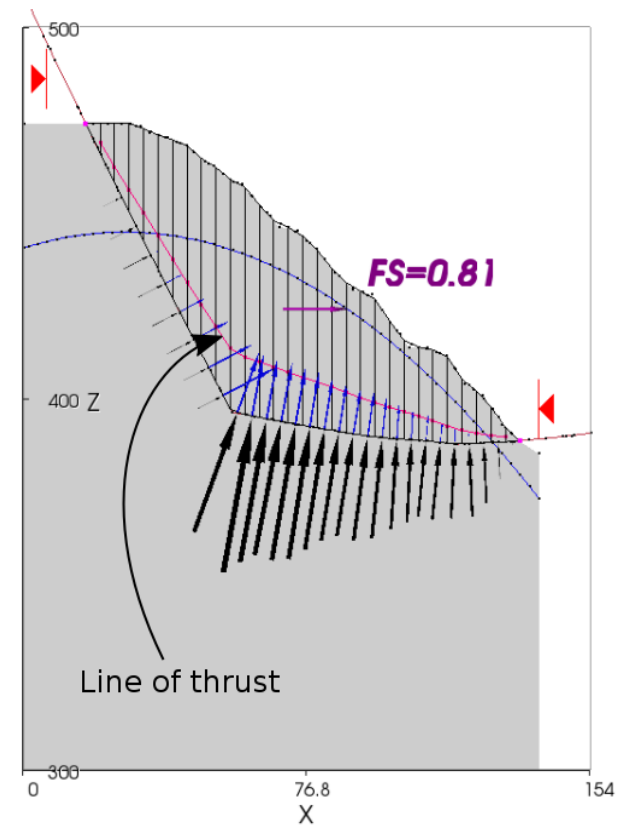

Figure 5 2D slope analysis showing vertical slices, forces acting at the base of slice, and line of thrust 


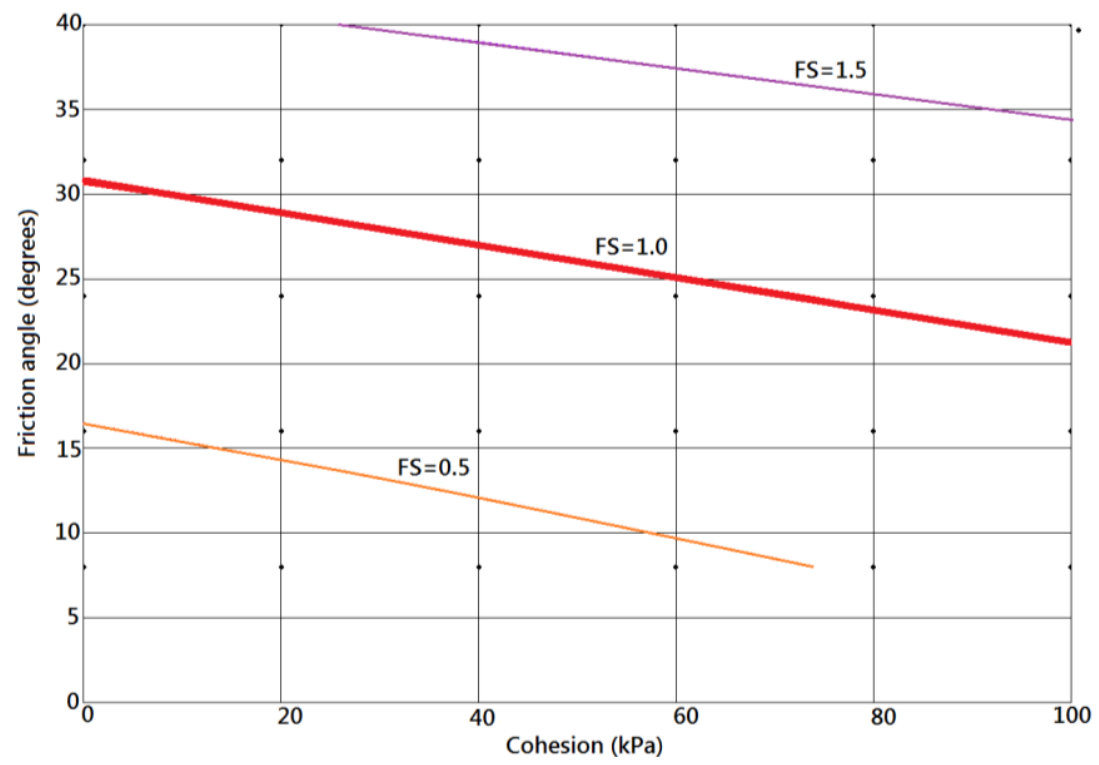

Figure 6 2D slope - friction angle versus cohesion for intervals of FS

When we use the strengths associated with a 3D FS of 1.0 in the $2 \mathrm{D}$ analysis, we get a lower FS. Using $\mathrm{c}=0$, $\varnothing=25^{\circ}$ for a $2 \mathrm{D}$ analysis, we get a FS of 0.81 as shown on Figure 5 .

Compared with the 3D results above, the friction angle corresponding to a FS of unity is now $31^{\circ}$.

\subsection{Comparison with polyhedral modelling}

Polyhedral representation of rock block assemblages have been useful for the assessment of rigid block stability, in situ fragmentation and other geotechnical analyses. For the purpose of demonstrating the benefits associated with the application of limit equilibrium analysis on the open pit example described, an analysis using a polyhedral modeller has been performed.

Polyhedral modellers have traditionally required simplifications such as cubic or hexahedral representations of the volume being simulated, very small numbers of discontinuities (beds, faults and joint fractures), the assumption of planar topologies for these discontinuities, the assumption of infinite persistence, and the assumption that blocks can only form as tetra-, penta- or hexahedra. The third and fourth simplifications are related and impose critical limits on the ability of a modeller to represent jointed rock masses found in nature since such rock masses consist of irregular rock blocks or concave polyhedra. The polyhedral modeller utilised in this paper represents an evolution of modellers outlined by Lin et al. (1987), Jing and Stephansson (1994), Jing (2000), and Lu (2002). The modeller is described in detail in Elmouttie et al. (2010). In brief, the algorithm accepts a polygon 'soup' as input (such as that defined by a discrete fracture network, or DFN) and detects all vertices, edges and faces resulting from mutual intersections of the polygons or triangulated surfaces. A face-tracing algorithm is then used to detect polyhedra within the volume of interest. This modeller has been utilised in the Siromodel software developed for the Large Open Pit Slope Stability Project managed by CSIRO. Once the polyhedra are detected, kinematic stability analysis using a modified version of that described in (Warburton 1981) is applied to each block to assess failure modes, and a rigid block limit equilibrium analysis is applied to calculate the block's FS.

An analysis was performed using the structural data as previously described. The limitations associated with this approach are immediately apparent. Figure 7 shows the resulting wedge assessed by the software as being kinematically stable. This is due to the presence of asperities on the non-planar fault surfaces, preventing the kinematic analysis from detecting the wedge failure mode. 


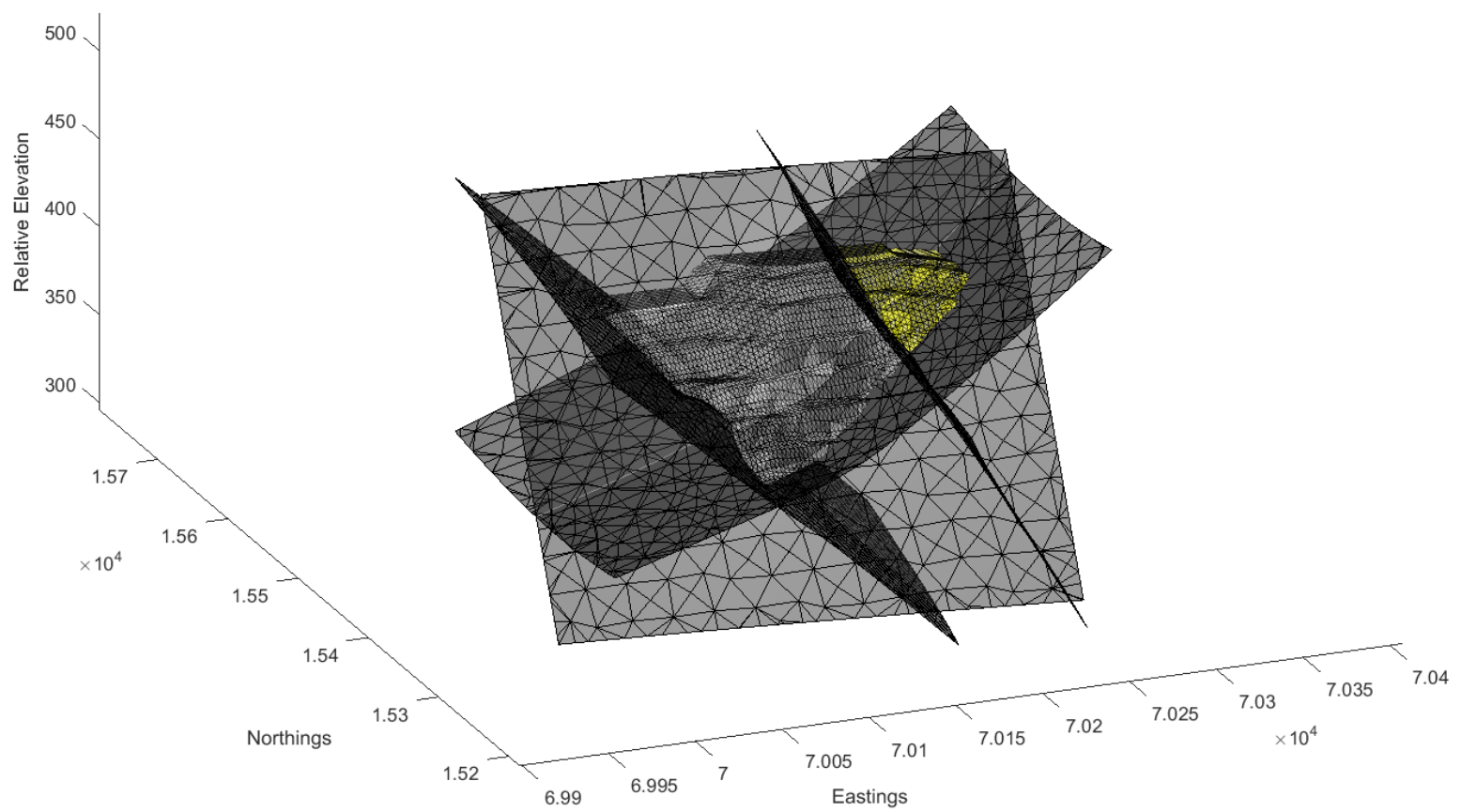

Figure 7 Representation of failure surface using triangulated curved fault surfaces

If the fault surfaces are represented as planar as shown in Figure 8 then a potential wedge failure is identified. However, the stability analysis is limited to double plane sliding (with high FS) and no account for deformation or shear failure is made.

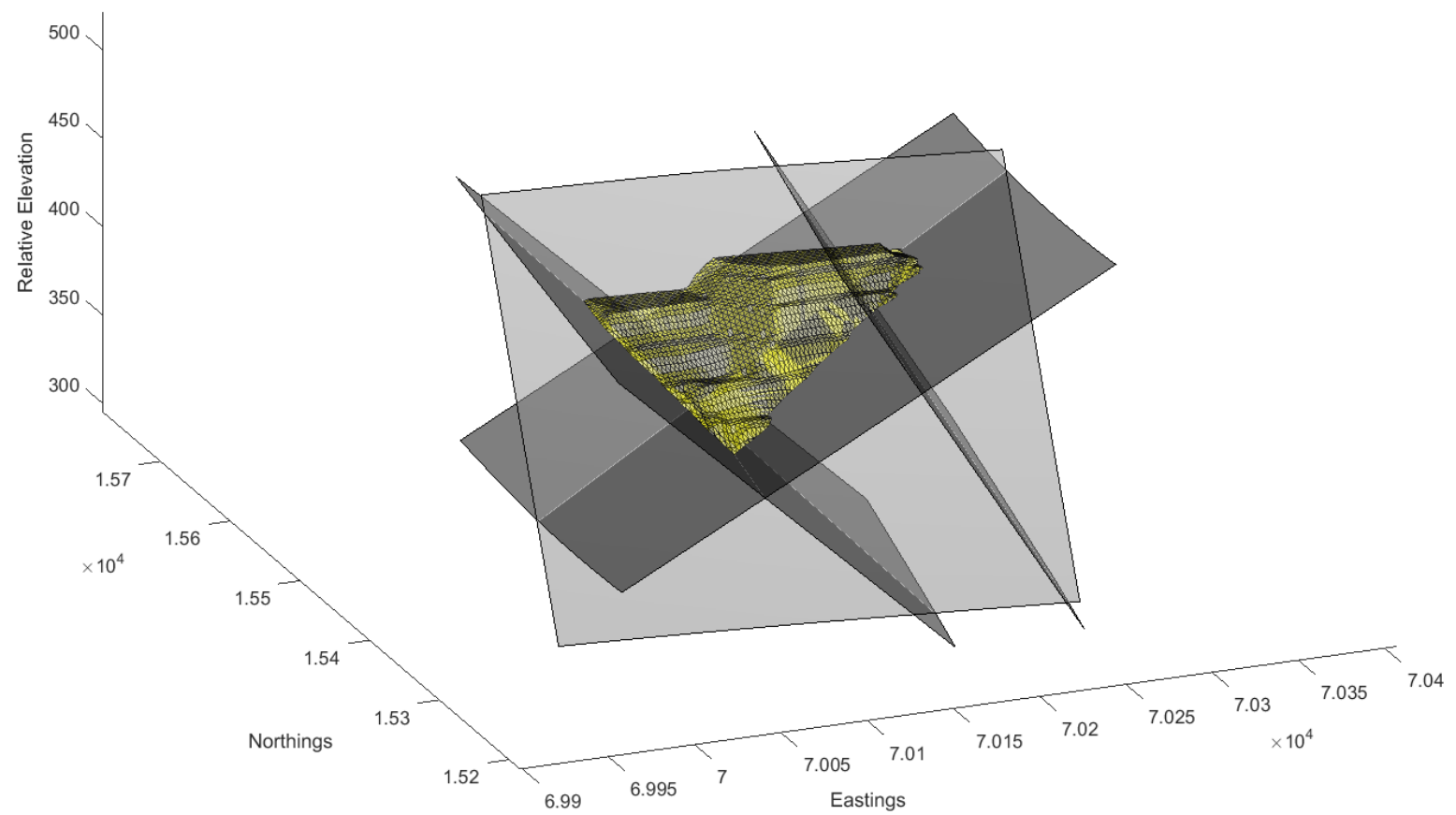

Figure 8 Representation of failure surface assuming planar fault surfaces

\section{Discussion}

Our results show that a 3D limit equilibrium stability analysis of a complex rock failure provides a lower estimate of in situ shear strengths than obtained from an equivalent 2D analysis. Forward analyses based on the 2D back-analysis would therefore be unconservative. At the same time the estimated in situ shear strength is greater than shear strengths obtained from laboratory testing indicating that sample disturbance or testing errors might lead to overly conservative forward calculations. 
In the analyses we have carried out, the strength values apply to the whole failure surface. As this failure surface is a composite of fault surfaces, we can only calculate an average strength over the total area of failure surface.

Pit slope failures provide an opportunity to build up an understanding of the distribution of shear strengths that apply to similar failure surfaces around the pit. The cross plot shown on Figure 4 does not provide a unique solution. However if the same analysis were carried out on other slope failures with similar geology, there would be an opportunity to compare multiple solutions and provide upper and lower bounds to the Mohr Coulomb strength parameters.

A good example of this was presented by Sancio (1981), who carried out back-calculations of stability on a number of slope failures in the same weathered rock along a freeway in Caracas, Venezuela. His cross plot is shown on Figure 9; this also shows the bounds placed on the strengths.

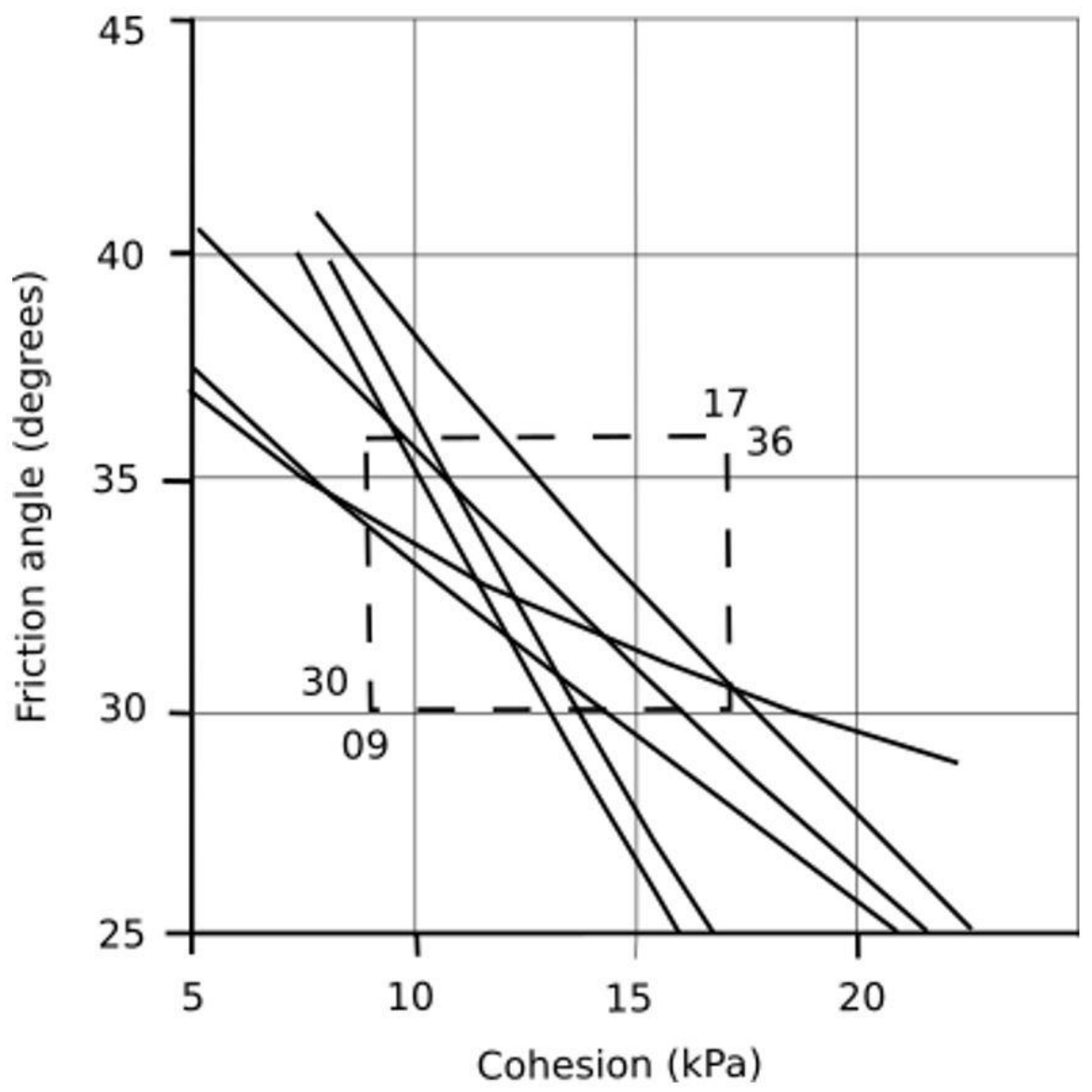

Figure 9 Multiple solutions of friction angle versus cohesion for six rock failures (after Sancio 1981)

\section{Conclusion}

Deriving appropriate shear strengths to use in a slope stability analysis is one of the more difficult parts of the slope design process. We have used a limit equilibrium based slope stability software capable of simultaneous 2D and 3D analyses to investigate the implications of analysis dimensionality. Our analysis of a structurally constrained pit slope failure at an open pit mine suggests that for this example, laboratory derived shear strengths might provide a lower bound and that back-calculated shear strengths using a 2D analysis could provide an upper bound.

Our work has shown that it is important to consider the 3D nature of open pit slope failures. We also show the benefits of using the full 3D limit equilibrium approach versus the constrained failure mechanism analysis using polyhedral/planar failure surface constraints. 
There are many uncertainties involved with any slope stability analysis, however it is important that the method of analysis used to derive strengths from back-analysis is the same as subsequently used for slope design. That will at least ensure that where there are errors in the analysis they may be compensated for.

Systematic documentation of open pit slope failures and careful back-analysis should lead to a better understanding of applicable shear strengths, and more efficient pit slope designs.

\section{Acknowledgement}

Robert Pyke (Walnut Creek, California) provided helpful review of this paper. David Stewart was the geotechnical engineer with Macraes Mining Company Ltd at the time of the RH28 slope failure. Andy Winneke is the present open pit geotechnical engineer at Macraes mine (now operated by OceanaGold Corp). We acknowledge OceanaGold's contribution to the data used in this paper.

\section{References}

ARANZ Geo 2016, www.leapfrog3d.com

Chapple, AP 1998, 'An engineering geological investigation into pit slope stability at Macraes Gold Mine, Macraes Flat, Otago, New Zealand', unpublished MSc thesis, University of Canterbury.

Duncan, JM, Wright, SG \& Brandon, TL 2014, Soil strength and slope stability, John Wiley \& Sons, Inc.

Elmouttie, M, Krahenbuhl, G \& Soliman, A 2016, 'A new excavation analysis method for slope design using discrete fracture network based polyhedral modelling', Computers and Geotechnics, vol. 76, pp. 93-104.

Elmouttie, M, Poropat, G, \& Krahenbuhl, G 2010, 'Polyhedral modelling of rock mass structure', International Journal of Rock Mechanics \& Mining Science, vol. 47, pp. 544-552.

Jing, L 2000, 'Block system construction for three-dimensional discrete element models of fractured rocks', International Journal of Rock Mechanics \& Mining Science, vol. 37, pp. 645-659.

Jing, L \& Stephansson, O 1994, 'Topological identification of block assemblages for jointed rock masses', International Journal of Rock Mechanics \& Mining Science and Geomechanics Abstracts, vol. 31, pp. 163-172.

Lee, MC, Batt, WD \& Robinson, PC 1989, 'The Round Hill gold-scheelite deposit, Macraes Flat, Otago, New Zealand', in Mineral Deposits of New Zealand, The Gordon J. Williams Memorial Volume Monograph 13, The Australasian Institute of Mining and Metallurgy, pp 173-179.

Lin, D, Fairhurst, C \& Starfield, A 1987, 'Geometrical identification of three dimensional rock block systems using topological techniques', International Journal of Rock Mechanics \& Mining Science and Geomechanics Abstracts, vol. 26, no. 6, pp. 331-338.

Lu, J 2002, 'Systematic identification of polyhedral rock blocks with arbitrary joints and faults', Computers and Geotechnics, vol. 29, pp. 49-72.

Sancio, RT 1981, 'The use of back-calculations to obtain the shear and tensile strength of weathered rocks', in Proceedings of the International Symposium on Weak Rock, Tokyo, A.A.Balkema, Rotterdam, pp. 647-652.

Spencer, E 1967, 'A method of analysis of the stability of embankments assuming parallel inter-slice forces', Geotechnique, vol. 17, no. 1 , pp. 11-26.

TAGAsoft 2016, www.tagasoft.com

Warburton, PM 1981, 'Vector stability analysis of an arbitrary polyhedral rock block with any number of free faces', International Journal of Rock Mechanics \& Mining Science, vol. 18, no. 5, pp. 415-442. 